\title{
Substratos na aclimatização de Pfaffia glomerata (Spreng) Pedersen produzida in vitro sob diferentes doses de sacarose
}

\author{
Substrates in the acclimatization of Pfaffia glomerata (Spreng.) Pedersen produced in vitro under \\ different levels of sucrose
}

Etiane Caldeira Skrebsky ${ }^{1}$ Fernando Teixeira Nicoloso ${ }^{2}$ Joseila Maldaner $^{3}$

\section{RESUMO}

\begin{abstract}
Este trabalho teve como objetivo selecionar substratos para a aclimatização de plântulas de Pfaffia glomerata produzidas in vitro sob diferentes concentrações de sacarose. Os tratamentos consistiram de uma combinação bifatorial (5x3) entre cinco doses de sacarose (15, 30, 45, 60 e $\left.75 \mathrm{~g} \mathrm{~L}^{-1}\right)$, presentes no meio de cultura in vitro, e três substratos [Plantmax ${ }^{\circledast}$ Hortaliças, Plantmax ${ }^{\circledast}+$ Solo $(1: 1 \mathrm{v} / \mathrm{v})$ e Vermiculita (granulometria média) + Solo (ARGISSOLO VERMELHO Distrófico arênico) (1:1 v/v)] utilizados na aclimatização ex vitro. Foram realizadas determinações das características físicas e químicas dos substratos, bem como avaliações do crescimento e da sobrevivência das plantas tanto durante o cultivo in vitro como no ex vitro. Plantas provenientes do cultivo in vitro na presença de 45 a $60 \mathrm{~g} \mathrm{~L}^{-1}$ de sacarose apresentaram melhor aclimatização ex vitro. As combinações dos substratos Vermiculita + solo $(1: 1 \mathrm{v} / \mathrm{v})$ e Plantmax ${ }^{\circledast}+\operatorname{solo}(1: 1 \mathrm{v} / \mathrm{v})$ proporcionaram maior crescimento às plantas durante a última fase de aclimatização (cultivo sob sombrite), provavelmente devido a possuírem maior porosidade total. Entretanto, o uso isolado de Plantmax ${ }^{\circledast}$ aumentou a sobrevivência das plantas cultivadas a campo, fato relacionado a esse substrato possuir os maiores valores de capacidade de retenção de água, de água facilmente disponível e de água disponível.
\end{abstract}

Palavras-chave: ginseng brasileiro, produção de mudas, micropropagação.

\section{ABSTRACT}

This work was aimed at selecting substrates on the ex vitro acclimatization of Pfaffia glomerata produced in vitro under different sucrose levels. The treatments consisted of a bifactorial combination (5x3) between five sucrose levels (15, $30,45,60$, and $\left.75 \mathrm{~g} \mathrm{~L}^{-1}\right)$, present in the in vitro culture, and three substrates [Plantmax ${ }^{\circledast}$; Plantmax ${ }^{\circledast}+$ soil $(1: 1 \mathrm{v} / \mathrm{v})$, and vermiculite (middle size) + soil (Paleudalf) $(1: 1 \mathrm{v} / \mathrm{v})]$ used in

\begin{abstract}
the ex vitro acclimatization steps. Physical and chemical evaluations of the substrates were carried out as well as evaluations of plant growth and survival for both in vitro and ex vitro cultures. Plants obtained from in vitro cultures in the presence of 45 to $60 \mathrm{~g} \mathrm{~L}^{-1}$ sucrose showed better ex vitro acclimatization. The substrate combinations vermiculite + soil and Plantmax ${ }^{\circledR}+$ soil gave rise greater growth to plants during the last acclimatization step (partially shady natural environment), probably due to having greater total porosity. However, the isolated use of Plantmax ${ }^{\circledR}$ increased the plant survival under field conditions because this substrate showed the greatest values for water retention capacity, easily available water and available water.
\end{abstract}

Key words: brazilian ginseng, seedling production, micropropagation.

\section{INTRODUÇÃO}

Pfaffia glomerata (Spreng.) Pedersen, conhecida como ginseng brasileiro, é uma das espécies da família Amaranthaceae de grande interesse comercial na forma de fitomedicamentos e suplementos alimentares. A intensa exploração predatória das reservas naturais justifica a elaboração de planos de manejo ou projetos de cultivo para $\boldsymbol{P}$. glomerata (MONTANARI JÚNIOR, 1999). Portanto, a micropropagação parece ser uma alternativa viável, pois permite a obtenção de um grande número de plantas com autenticidade varietal em qualquer época do ano (GRATTAPAGLIA \& MACHADO, 1998; NICOLOSO et al., 2001).

${ }^{1}$ Programa de Pós-graduação em Agronomia, Universidade Federal de Santa Maria (UFSM), Santa Maria, RS, Brasil.

${ }^{2}$ Departamento de Biologia, UFSM, Campus Universitário, Camobi, 97105-900, Santa Maria, RS, Brasil. E-mail: nicoloso@base.ufsm.br. Autor para correspondência.

${ }^{3}$ Curso de Ciências Biológicas, UFSM, Santa Maria, RS, Brasil. 
Um número expressivo de espécies vegetais micropropagadas não sobrevive quando transferidas das condições in vitro para ambiente de casa de vegetação ou campo (HARARIKA, 2003). A maioria das espécies cultivadas in vitro requer um processo de aclimatização, o qual consiste de modificações morfológicas, anatômicas e fisiológicas necessárias às plantas para que possam sobreviver e crescer vigorosamente em um novo ambiente (GRATTAPAGLIA \& MACHADO, 1998; CARVALHO et al., 1999; HARARIKA, 2003).

O mecanismo pelo qual a fonte e a concentração de carboidratos utilizados no cultivo in vitro influenciam o processo de aclimatização ex vitro das plantas não está esclarecido (LEITE et al., 2000). Os autores retrocitados sugerem manter a sacarose no nível normalmente utilizado (30 $\left.\mathrm{g} \mathrm{L}^{-1}\right)$ ou, até mesmo, aumentá-lo numa fase anterior a aclimatização. Esse pré-condicionamento em altas concentrações de sacarose aumentaria as reservas de carboidratos armazenados pelas folhas, aumentando, assim, a energia disponível para as plântulas durante o processo de aclimatização (CALVETE, 1998; SKREBSKY et al., 2004). Em Cocos nucifera $L$., a presença de sacarose em concentração moderada $\left(22 \mathrm{~g} \mathrm{~L}^{-1}\right)$ diminui a fotossíntese, porém aumenta a sobrevivência, fato que sugere que tanto a fotossíntese in vitro como as reservas de sacarose exógenas contribuem para o estabelecimento a campo e o crescimento das plântulas (FUENTES et al., 2005).

Outro fator importante envolvido na aclimatização $\boldsymbol{e x}$ vitro é o substrato utilizado na preparação das mudas, pois ele pode facilitar ou impedir o crescimento destas últimas conforme suas propriedades físico-químicas. O processo de enraizamento in vitro em meio solidificado com ágar pode produzir raízes não funcionais (ALDRUFEU, 1987). Este autor observou que, na aclimatização de plântulas Pelargonium zonale, a adição de $20 \mathrm{~g} \mathrm{~L}^{-1}$ de sacarose ao meio de cultura aumentou a percentagem de enraizamento e o número de raízes por planta. Por outro lado, o comprimento das raízes dependeu do substrato usado.

As características do substrato como o elevado espaço de aeração associado à elevada capacidade de retenção de água são fatores fundamentais durante a aclimatização (CALVETE, 1998). Embora o substrato possa ser formado por um único material, dificilmente será encontrado um que suprirá todas as características positivas necessárias. Por essa razão, os substratos em geral representam a mistura de dois ou mais materiais, sendo que um destes, o condicionador de substratos, irá promover a correção das características de forma a otimizar as condições de uso (KÄMPF, 2000).

Este trabalho teve como objetivo selecionar substratos para a aclimatização de plântulas de $\boldsymbol{P}$. glomerata produzidas in vitro sob diferentes concentrações de sacarose.

\section{MATERIAL E MÉTODOS}

Experimento I - Esse experimento teve como objetivo produzir plantas in vitro de Pfaffia glomerata, submetidas a diferentes doses de sacarose, para serem utilizadas na aclimatização ex vitro (Experimento II). Como fonte de explantes, foram utilizados segmentos nodais (1,0cm de comprimento e sem folhas) de plantas de $\boldsymbol{P}$. glomerata cultivadas in vitro em meio de cultura MS (MURASHIGE \& SKOOG, 1962), segundo metodologia descrita por NICOLOSO et al. (2001).

Os tratamentos consistiram de cinco doses de sacarose (15, 30, 45, 60 e $\left.75 \mathrm{~g} \mathrm{~L}^{-1}\right)$ suplementadas ao meio de cultura in vitro, com 90 repetições. A parcela experimental consistiu de um tubo de ensaio $\left(147,26 \mathrm{~cm}^{3}\right.$ de volume interno) contendo $10 \mathrm{~mL}$ de meio $\mathrm{MS}$, solidificado com $0,6 \%$ de ágar, e um explante caulinar. $\mathrm{O}$ pH do meio de cultivo foi ajustado para 5,8 antes da inclusão do ágar e da autoclavagem (1atm, $120^{\circ} \mathrm{C}$, $15 \mathrm{~min})$. O cultivo dos explantes foi realizado em sala de crescimento com temperatura de $25 \pm 2^{\circ} \mathrm{C}$, fotoperíodo de $16 \mathrm{~h}$ e intensidade luminosa de $35 \mu \mathrm{mol} \mathrm{m} \mathrm{m}^{-2} \mathrm{~s}^{-1}$ fornecida por lâmpadas fluorescentes extra luz do dia (Philips). Os recipientes de cultivo foram fechados com folha de papel alumínio e filme plástico PVC.

Aos 7, 8, 9, 10, 11 e 12 dias após a inoculação (DAI) dos explantes, avaliou-se o número de raízes por plântula. Já aos 10 e 25 DAI, avaliou-se a altura de brotações, o número de segmentos nodais por brotação e a matéria seca total das plantas.

Utilizou-se o delineamento experimental inteiramente casualizado. Das 90 repetições, 10 foram utilizadas para a determinação da matéria seca das plantas aos 25 DAI.

Experimento II - Esse experimento foi elaborado utilizando plântulas de $\boldsymbol{P}$. glomerata provenientes do cultivo in vitro e teve como objetivo selecionar substratos para a aclimatização ex vitro. Os tratamentos consistiram de uma combinação bifatorial (5x3) entre cinco doses de sacarose (15, 30, 45, 60 e $75 \mathrm{~g}$ $\mathrm{L}^{-1}$ ), presentes no meio de cultura in vitro, e três substratos [Plantmax ${ }^{\circledR}$ Hortaliças; Plantmax ${ }^{\circledR}+$ Solo (1:1 v/v); Vermiculita (granulometria média) + Solo (ARGISSOLO VERMELHO Distrófico arênico) (1:1 v/ v)] utilizados na aclimatização ex vitro.

Ciência Rural, v.36, n.5, set-out, 2006. 
O processo de aclimatização ex vitro consistiu de três fases, segundo o método parcialmente modificado e descrito para a $\boldsymbol{P}$. glomerata por SKREBSKY et al. (2004). Resumidamente, após o cultivo in vitro, por período de 25 dias, e de abertura dos tubos de cultivo em sala de crescimento, por período de três dias (1ª etapa), fez-se a transferência das plântulas para recipientes plásticos $\left(350 \mathrm{~cm}^{3}\right)$ contendo $250 \mathrm{~cm}^{3}$ dos três substratos testados. A unidade experimental consistiu de uma planta por recipiente. Nessa etapa de aclimatização (2 $2^{\mathrm{a}}$ etapa), as plantas permaneceram por 15 dias em sala de crescimento, sob as mesmas condições utilizadas para o cultivo in vitro, com exceção da umidade relativa do ar, a qual foi de $60-70 \%$. Na seqüência, as plantas foram transferidas para um telado de sombrite (malha 50\% de extinção de luz), onde ficaram mais 15 dias (3a etapa). A umidade do substrato, independentemente da fase de aclimatização, foi mantida entre 45 e $60 \%$ da capacidade de recipiente (KÄMPF, 2000). Após essa etapa, as plantas foram transplantadas para solo (ARGISSOLO VERMELHO Distrófico arênico) em condições de campo, em uma área experimental pertencente ao Departamento de Fitotecnia da Universidade Federal de Santa Maria, RS. Nesse processo, as mudas aclimatizadas foram retiradas do recipiente plástico de cultivo, porém se manteve intacto a estrutura do substrato que abrigava as raízes, procedimento que foi adequado ao pegamento das mudas. O espaçamento utilizado no plantio foi de $1,0 \mathrm{~m}$ entre linhas e de $0,60 \mathrm{~m}$ entre plantas, com covas de $\pm 0,25 \mathrm{~m}$ de profundidade e $25 g$ de adubo N-P-K (5-20-20) por cova.

Aos três dias após a abertura dos tubos ( $1^{\text {a }}$ fase da aclimatização), avaliaram-se a altura de brotações, o número de segmentos nodais por brotação e a matéria seca total das plantas. Já aos 15 dias do cultivo em sala de crescimento ( 2 a fase) e sob sombrite (3a fase), avaliaram-se a altura e a matéria seca das plantas. Ao final de cada período de aclimatização, determinou-se a porcentagem de sobrevivência.

Utilizou-se o delineamento experimental inteiramente casualizado. Das 80 repetições levadas à 1ํㅗㄹ etapa de aclimatização, grupos de 10 repetições foram usados para a avaliação da matéria seca total das plantas no final de cada etapa da aclimatização.

As determinações dos parâmetros físicos e químicos dos substratos foram realizadas como segue: densidade seca (FERMINO, 1996); porosidade total, espaço de aeração, água disponível e água facilmente disponível (DE BOODT \& VERDONK, 1972); capacidade de retenção de água (ANDRIOLO \& POERSCHKE, 1997); pH e capacidade de troca de cátions (TEDESCO et al., 1996).
Foi realizada a análise de variância para todas as variáveis. Em caso significativo, nível de 5\% de probabilidade de erro, fez-se a análise de regressão para o fator concentração de sacarose e por comparação de médias (teste Tukey) para o fator tipo de substratos.

\section{RESULTADOS E DISCUSSÃO}

De acordo com os resultados obtidos, verificou-se que o número de raízes apresentou, a partir dos 9 dias após a inoculação (DAI), comportamento quadrático em relação à concentração de sacarose, cuja dose de máxima eficiência técnica estimada (DMET) ficou entre 30 e $45 \mathrm{~g} \mathrm{~L}^{-1}$ (Figura 1a). A altura de brotações (Figura 1b), o número de segmentos nodais por brotação (Figura 1c) e a matéria seca total da plântula (Figura 1d), avaliada aos 25 DAI, sob cultivo in vitro, bem como aos três dias após abertura (DAA) dos tubos de ensaio (1a etapa da aclimatização), também apresentaram comportamento quadrático à concentração de sacarose, com a DMET entre 45 e 60g $\mathrm{L}^{-1}$. Resultados semelhantes a esses foram obtidos por NICOLOSO et al. (2003); SKREBSKY et al. (2004), sendo que a elevação da concentração de sacarose de 30 até $60 \mathrm{~g} \mathrm{~L}^{-1}$ promoveu maior produção de biomassa dos órgãos de $\boldsymbol{P}$. glomerata cultivada in vitro.

Após o cultivo ex vitro em sala de crescimento por 15 dias, observou-se que não houve interação entre as doses de sacarose e os substratos utilizados na matéria seca total da planta, a qual apresentou comportamento quadrático à concentração de sacarose com DMET de $45 \mathrm{~g} \mathrm{~L}^{-1}$ (Figura 1e). Nessa etapa de aclimatização, o substrato que proporcionou maior produção de biomassa foi a combinação de Vermiculita + Solo (1:1 v/v), seguido do Plantmax ${ }^{\circledR}+$ Solo (1:1 v/v) e Plantmax ${ }^{\circledast}$, que não diferiram entre si (Tabela 1).

Aos 5, 10 e 15 dias do cultivo em sala de crescimento, não houve interação entre as

Tabela 1 - Efeito de três substratos [Plantmax ${ }^{\circledR}(\mathrm{P})$; Plantmax ${ }^{\circledR}+$ Solo $(\mathrm{P}+\mathrm{S})$ e Vermiculita média + Solo $(\mathrm{V}+\mathrm{S})]$ na matéria seca total de plantas de Pfaffia glomerata aos 15 dias sob cultivo em sala de crescimento e sob sombrite.

\begin{tabular}{lcc}
\hline Substratos & $\begin{array}{c}\text { Cultivo em sala de } \\
\text { crescimento }\end{array}$ & $\begin{array}{c}\text { Cultivo sob } \\
\text { sombrite }\end{array}$ \\
\hline & \multicolumn{2}{c}{ g planta $^{-1}$} \\
\cline { 2 - 3 } $\mathrm{V}+\mathrm{S}(1: 1 \mathrm{v} / \mathrm{v})$ & $0,1218 \mathrm{a}^{*}$ & $0,3684 \mathrm{a}$ \\
$\mathrm{P}+\mathrm{S}(1: 1 \mathrm{v} / \mathrm{v})$ & $0,0852 \mathrm{~b}$ & $0,3299 \mathrm{a}$ \\
$\mathrm{P}$ & $0,0709 \mathrm{~b}$ & $0,2592 \mathrm{~b}$ \\
\hline
\end{tabular}

* Médias seguidas pelas mesmas letras na coluna não diferem entre si ao nível de 5\% pelo teste de Tukey. 
concentrações de sacarose usadas in vitro e os substratos usados no cultivo ex vitro na altura de plantas, a qual teve resposta quadrática à sacarose com DMET próxima a 48g L ${ }^{-1}$ (Figura 2a). Resultados semelhantes a estes foram registrados para o morangueiro (Fragaria $x$ ananassa Duch.) por CALVETE (1998) e para a P. glomerata por SKREBSKY et al. (2004).

A porcentagem de sobrevivência na $2^{a}{ }^{a}$ etapa da aclimatização foi menor para as plantas produzidas in vitro nas doses de 15 e $75 \mathrm{~g} \mathrm{~L}^{-1}$ de sacarose, independentemente do substrato testado (Figura 2b). Portanto, o maior crescimento observado nas plantas cultivadas in vitro na presença de sacarose entre 30 e $60 \mathrm{~g} \mathrm{~L}^{-1}$, em relação àquelas cultivadas com 15 e $75 \mathrm{~g} \mathrm{~L}^{-1}$, não afetou negativamente o início da aclimatização (fase da sala de crescimento em substrato).

Nas condições de cultivo sob sombrite por 15 dias (3a etapa da aclimatização), a acumulação de biomassa apresentou interação entre as doses de sacarose usadas in vitro e os substratos utilizados $\boldsymbol{e x}$ vitro. A matéria seca total das plantas apresentou resposta quadrática à sacarose com DMET próximo a $45 \mathrm{~g} \mathrm{~L}^{-1}$ (Figura 1f) e os substratos Vermiculita + Solo $(1: 1 \mathrm{v} / \mathrm{v})$ e Plantmax ${ }^{\circledR}+\operatorname{solo}(1: 1 \mathrm{v} / \mathrm{v})$ foram os melhores (Tabela 1). Já a altura de plantas, avaliada aos 5, 10 e 15 dias, não apresentou interação entre as doses de sacarose e os substratos, apresentando resposta quadrática à sacarose, com DMET de $50 \mathrm{~g} \mathrm{~L}^{-1}$ (Figura 2c). Em Cocos nucifera L., a presença de sacarose em concentração moderada $\left(22 \mathrm{~g} \mathrm{~L}^{-1}\right)$ diminui a fotossíntese, porém aumenta a sobrevivência, fato que sugere que tanto a fotossíntese in vitro como as reservas de sacarose exógenas contribuem para o estabelecimento a campo e o crescimento das plântulas (FUENTES et al., 2005). Resultados semelhantes foram observados em plântulas de Nicotiana tabacum L. por KADLECEK et al. (2001) e em explantes de Actinidia deliciosa por ARIGITA et al. (2002).

Na 3a etapa da aclimatização, observou-se queda foliar aos 10 dias de cultivo, independentemente dos tratamentos testados. Essa observação vai ao encontro daquela registrada para o morangueiro (Fragaria x ananassa Duch.) por CALVETE (1998). A abscisão foliar durante a aclimatização de plantas cultivadas in vitro parece ser um fenômeno comum em resposta às mudanças fisiológicas e morfológicas devidas à alteração do ambiente. Até o final do período de cultivo sob sombrite, a sobrevivência das plantas durante o processo de aclimatização não sofreu influência dos tratamentos de sacarose e substratos, com exceção das plantas cultivadas na dose de $75 \mathrm{~g} \mathrm{~L}^{-1}$ de sacarose e na presença dos substratos Plantmax ${ }^{\circledR} \mathrm{e}$
Plantmax ${ }^{\circledast}+$ Solo (1:1 v/v), que apresentaram redução de $10 \%$ de sobrevivência (Figura 2d). Na aclimatização de Kielmeyera coreacea, Manihot esculenta, Ipomoea batatas e Rubus idaeus, o maior índice de sobrevivência dependeu da espécie, porém não sofreu influência de nenhum dos substratos testados (SILVA et al., 1995).

Resultados apresentados por HOFFMANN et al. (2001) para macieira demonstram que a sobrevivência das plantas entre 7 e 21 dias da aclimatização caiu para $85 \%$, em virtude do estresse sofrido na transferência das plantas do laboratório para a casa de vegetação. Porém, esses autores também observaram que, nos últimos dias do período de aclimatização, a sobrevivência manteve-se inalterada, indicando uma tendência a estabilização a partir dos 28 dias (4 semanas). Há autores que sugerem que ocorre uma queda drástica na sobrevivência das plantas em torno de duas semanas após o início da aclimatização, mencionando que este fato é causado pela baixa eficiência na troca do metabolismo heterotrófico para o autotrófico (HOFFMANN et al., 2001).

A duração do processo de aclimatização para $\boldsymbol{P}$. glomerata utilizada nesse trabalho foi de 5 semanas. SKREBSKY et al. (2004) utilizaram com sucesso um período de sete semanas na aclimatização dessa mesma espécie. Portanto, visando à produção comercial em larga escala, a diminuição do tempo de aclimatização obtida nesse trabalho pode ser um fator econômico de extrema importância na produção de mudas.

A altura das plantas transferidas para condições de campo, avaliada aos 5, 10 e 15 dias, não apresentou interação entre as doses de sacarose e os substratos. Entretanto, verificou-se que plantas oriundas do cultivo in vitro obtidas na presença de sacarose a $\pm 50 \mathrm{~g} \mathrm{~L}^{-1}$ apresentaram maior crescimento (Figura 2e). Quanto à sobrevivência aos 15 dias de cultivo a campo, o substrato Plantmax ${ }^{\circledR}$ isolado foi o melhor, seguido do substrato Vermiculita + Solo (1:1 v/ v) (Figura 2f). Já o substrato Plantmax ${ }^{\circledR}+$ solo proporcionou a menor sobrevivência de plantas. Possivelmente este resultado esteja relacionado à menor capacidade de retenção de água, à água disponível e à água facilmente disponível (Tabela 2).

Dos substratos utilizados, o Plantmax ${ }^{\circledR}$ apresenta valores de densidade próximos do ideal (Tabela 2), segundo parâmetros relatados por DE BOODT \& VERDONCK (1972). Para esses autores, substratos com densidade abaixo de $400 \mathrm{~g} \mathrm{~L}^{-1}$ fornecem pouca estabilidade às plantas, ficando estas sujeitas ao tombamento. Por outro lado, densidades altas podem prejudicar o crescimento de raízes. Os substratos 


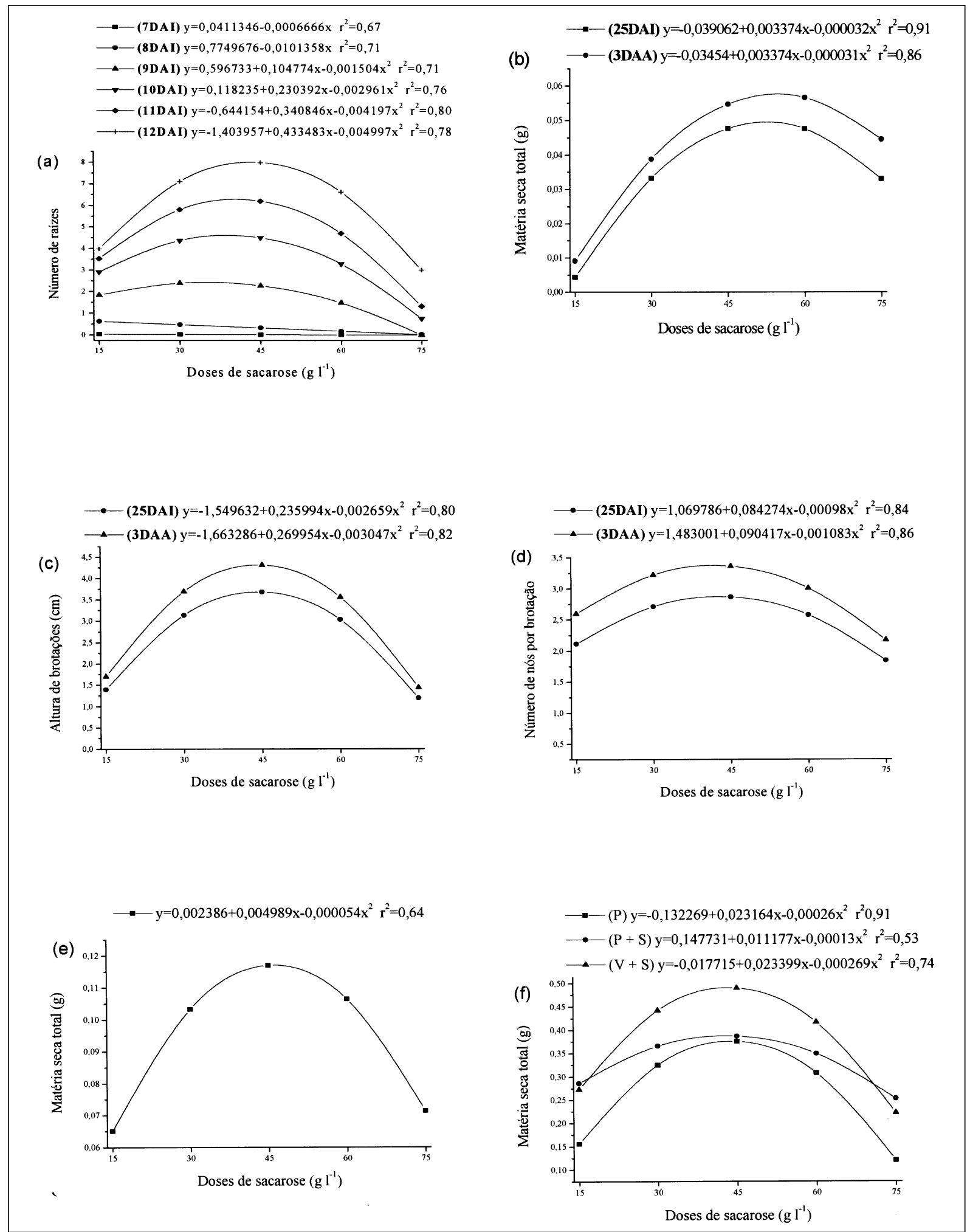

Figura 1 - Efeito de doses de sacarose no número de raízes (a), na matéria seca total (b), na altura de brotações (c) e no número de segmentos nodais por brotação (d) de plântulas de Pfaffia glomerata cultivadas in vitro e na abertura dos tubos durante a 1 etapa da aclimatização, bem como na matéria seca total dessas plantas durante as três etapas de aclimatização: na abertura dos tubos por 3 dias (d), em sala de crescimento por 15 dias (e) e sob sombrite por 15 dias (f). P (Plantmax®), P+S (Plantmax ${ }^{\circledR}+$ solo) e $\mathrm{V}+\mathrm{S}$ (vemiculita+solo). 


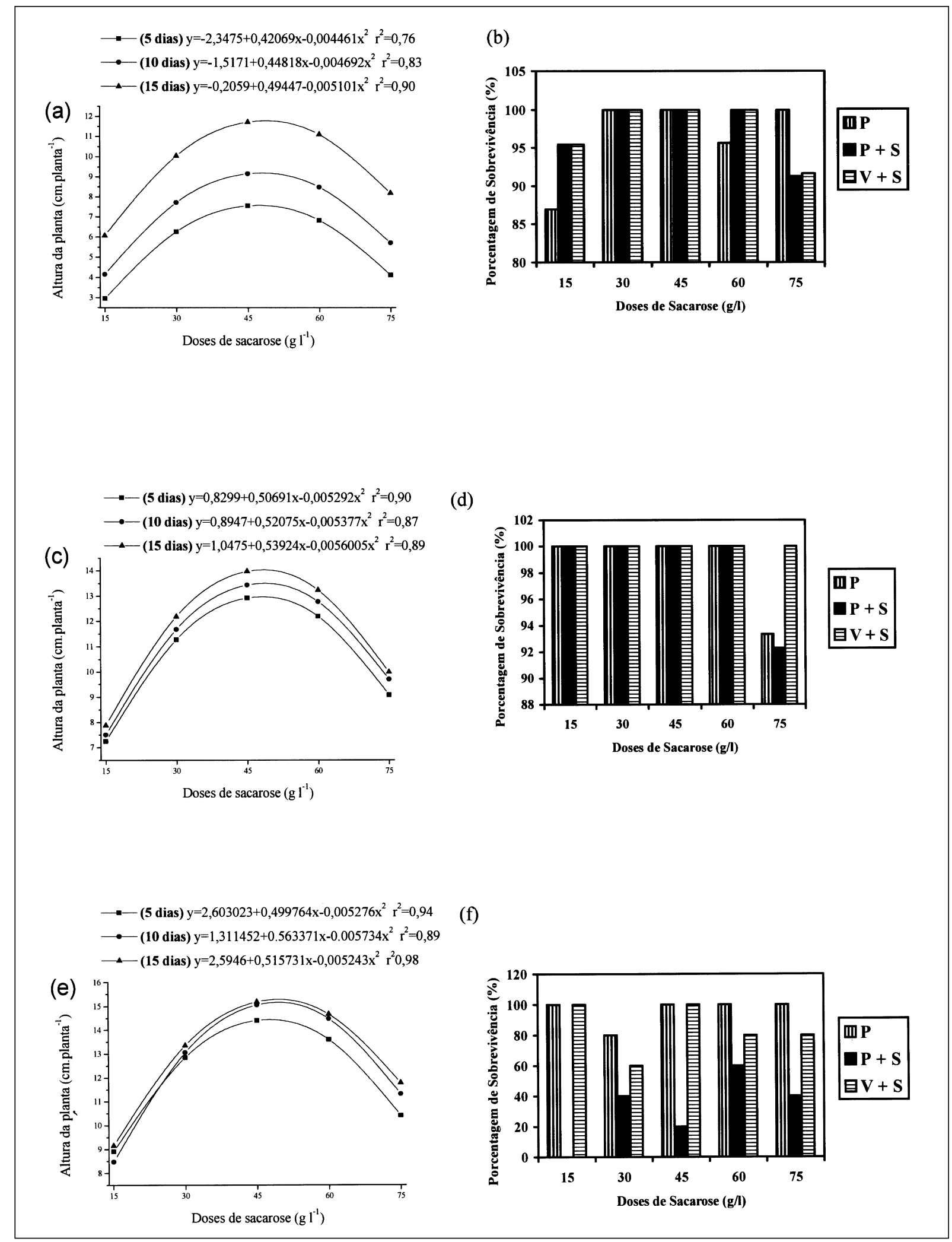

Figura 2 - Efeito de doses de sacarose e de substratos, respectivamente, na altura e na sobrevivência de plantas de Pfaffia glomerata cultivadas ex vitro em sala de crescimento (a, b), em sombrite (c, d) e a campo (e, f). P (Plantmax $\left.{ }^{\circledR}\right), P+S\left(P l a n t m a x{ }^{\circledR}+\right.$ solo) e V+S (vemiculita média + solo).

Ciência Rural, v.36, n.5, set-out, 2006. 
Plantmax $^{\circledast}+$ Solo (1:1 v/v) e Vermiculita + Solo (1:1 v/ v), por possuírem $50 \%$ de solo, apresentaram densidade considerada alta para a produção de mudas.

O Plantmax ${ }^{\circledR}$, usado isoladamente, foi o que apresentou maior capacidade de retenção de água (Tabela 2), fato que pode ter contribuído para diminuir as perdas elevadas de água pela evapotranspiração durante o período inicial de cultivo a campo. DUARTE (2002) recomenda usar substratos que possuam no mínimo 55\% de CRA.

Já o substrato Plantmax ${ }^{\circledR}+$ Solo $(1: 1 \mathrm{v} / \mathrm{v})$ apresentou maior porosidade total (PT) entre os substratos testados (Tabela 2). De acordo com DE BOODT \& VERDONCK (1972), valores de 95\% de PT ou superiores são considerados ideais, sendo que todos os substratos utilizados no presente trabalho se enquadram nessa característica.

O espaço de aeração é responsável pela manutenção de oxigênio às raízes. Substratos apresentando espaços de aeração entre 20 e 30\% são considerados ideais (DE BOODT \& VERDONCK, 1972), sendo o Plantmax ${ }^{\circledR}$ o único que se aproximou desse valor (Tabela 2).

Com relação aos valores de água disponível e de água facilmente disponível, apenas o substrato Plantmax $^{\circledR}$ apresentou valores dentro da faixa ideal (Tabela 2), segundo DE BOODT \& VERDONCK (1972).

Não houve diferença entre os três substratos testados em relação ao pH em água $(4,9)$. Entretanto, quanto à CTC, o substrato Plantmax ${ }^{\circledR}$ apresentou valores superiores $\left(30 \mathrm{Cmol}_{\mathrm{c}} \mathrm{dm}^{-3}\right.$ ) aos substratos Plantmax ${ }^{\circledR}+$ solo $\left(19,7 \mathrm{Cmol}_{\mathrm{c}} \mathrm{dm}^{-3}\right)$ e Vermiculita + solo $\left(18,2 \mathrm{Cmol}_{\mathrm{c}} \mathrm{dm}^{-3}\right)$, que não diferiram entre si. DUARTE (2002) considera valores ideais de CTC entre 10 e $30 \mathrm{meq} / 100 \mathrm{~g}$. Altos valores de CTC não somente reduzem a lixiviação de nutrientes como aumentam a capacidade de tamponamento, prevenindo amplas variações no $\mathrm{pH}$ e na disponibilidade de nutrientes. Segundo CALVETE (1998), características

Tabela 2 - Densidade seca (DS), capacidade de retenção de água (CRA), porosidade total (PT), espaço de aeração (EA), água facilmente disponível (AFD) e água disponível (AD) dos três substratos [Plantmax ${ }^{\circledR}(\mathrm{P})$; Plantmax $^{\circledR}+$ Solo $(\mathrm{P}+\mathrm{S})$ e Vermiculita média + Solo $(\mathrm{V}+\mathrm{S})]$ utilizados na aclimatização ex vitro da Pfaffia glomerata.

\begin{tabular}{lllllll}
\hline \multirow{2}{*}{ Substratos } & \multicolumn{1}{c}{ DS } & CRA & PT & EA & AD & AFD \\
\hline & $\mathrm{g} \mathrm{L}^{-1}$ & & & $\%$ & & \\
\cline { 2 - 7 } $\mathrm{P}+\mathrm{S}(1: 1 \mathrm{v} / \mathrm{v})$ & $1112,3 \mathrm{a}^{*}$ & $24,1 \mathrm{c}$ & $164,5 \mathrm{a}$ & $5,0 \mathrm{~b}$ & $6,8 \mathrm{~b}$ & $3,9 \mathrm{~b}$ \\
$\mathrm{~V}+\mathrm{S}(1: 1 \mathrm{v} / \mathrm{v})$ & $1093,4 \mathrm{a}$ & $28,5 \mathrm{~b}$ & $157,3 \mathrm{~b}$ & $6,5 \mathrm{~b}$ & $9,0 \mathrm{~b}$ & $5,5 \mathrm{~b}$ \\
$\mathrm{P}$ & $411,8 \mathrm{~b}$ & $54,1 \mathrm{a}$ & $111,0 \mathrm{c}$ & $14,2 \mathrm{a}$ & $28,3 \mathrm{a}$ & $24,5 \mathrm{a}$ \\
\hline
\end{tabular}

* Médias seguidas pelas mesmas letras na coluna não diferem entre si ao nível de $5 \%$ pelo teste de Tukey de disponibilidade de água, espaço de aeração e CTC são decisivos para o crescimento das mudas de morangueiro na etapa de aclimatização. De acordo com MACIEL et al. (2000), o substrato ideal deve apresentar baixa densidade, alta CTC, alta CRA e boa drenagem e aeração.

O substrato comercial Plantmax ${ }^{\circledR}$ é um exemplo de produto que está sendo utilizado para a formação de mudas de eucalipto, pinus, citrus, maracujazeiro, olerículas e também cafeeiros. Segundo HOFFMANN et al. (2001), o Plantmax ${ }^{\circledR}$ apresenta vantagem pela sua uniformidade de composição química e física, diferentemente do que pode ocorrer com o solo e distintos materiais orgânicos, os quais podem variar muito nas suas características. Já para NETO et al. (1999), o substrato comercial Plantmax ${ }^{\circledR}$ possui boas características físicas, mas necessita da complementação de nutrientes por meio da aplicação de solução nutritiva para se obterem mudas de melhor qualidade.

Avaliando o efeito de cinco substratos [Plantmax $^{\circledR}$; Vermiculita; Solo + Areia $(1: 1 \mathrm{v} / \mathrm{v})$; Composto orgânico + Areia (1:1 v/v) e Solo + Composto orgânico + Areia (2:2:1 v/v)] durante a aclimatização de plantas do porta-enxerto de macieira, HOFFMANN et al. (2001) concluíram que o substrato menos eficiente foi a vermiculita, sendo o Plantmax ${ }^{\circledR}$ o mais recomendado tanto para o crescimento da parte aérea quanto das raízes.

\section{CONCLUSÕES}

Para Pfaffia glomerata cultivada in vitro, sacarose nas doses de 45 a $60 \mathrm{~g} \mathrm{~L}^{-1}$ promove maior índice de aclimatização. Os substratos Vermiculita média + solo $(1: 1 \mathrm{v} / \mathrm{v})$ e Plantmax ${ }^{\circledR}+\operatorname{solo}(1: 1 \mathrm{v} / \mathrm{v})$ promoveram maior crescimento das plantas de Pfaffia glomerata na última fase de aclimatização (cultivo sob sombrite). Já o substrato Plantmax ${ }^{\circledR}$ usado isoladamente proporcionou o maior índice de sobrevivência das plantas cultivadas a campo.

\section{REFERÊNCIAS}

ALDRUfeU, A. Rooting and acclimatization of Pelargonium zonale plantlets. Acta Horticulturae, Leuven, v.212, p.361366, 1987.

ANDRIOLO, J.L.; POERSCHKE, P.R. Cultivo do tomateiro em substratos. Santa Maria: Universidade Federal de Santa Maria, 1997. 13p. (Informe Técnico, 2).

ARIGITA, L. et al. Influence of $\mathrm{CO}_{2}$ and sucrose on photosynthesis and transpiration of Actinidia deliciosa explants cultured in vitro. Physiologia Plantarum, Denmark, v.115, p.166-173, 2002. 
CALVETE, E.O. Concentração de sacarose in vitro e seleção de substratos para aclimatização ex vitro de morangueiro cv campinas (Fragaria ananassa Duch.). 1998. 108f. Tese (Doutorado em Agronomia) - Programa de Pós-graduação em Agronomia, Universidade Federal do Rio Grande do Sul.

CARVALHO, G.R. et al. Aclimatização de plantas de cafeeiro (Coffea arabica L.) propagadas “in vitro”. Ciência e Agrotecnologia, Lavras, v.23, n.3, p.483-490, 1999.

DE BOODT, M.; VERDONCK, O. The physical properties of the substrates in horticulture. Acta Horticulturae, Wageningen, v.26, p.37-44, 1972.

DUARTE, T.S. Substratos orgânicos para a produção de mudas de tomateiro. 2002. 69f. Dissertação (Mestrado em Agronomia) - Programa de Pós-graduação em Agronomia, Faculdade de Agronomia Eliseu Maciel.

FERMINO, M.H. Aproveitamento de resíduos industriais e agrícolas como alternativas de substratos hortícolas. 1996. 90f. Dissertação (Mestrado em Agronomia) - Programa de Pós-graduação em Agronomia, Universidade Federal do Rio Grande do Sul.

FUENTES, G. et al. Exogenous sucrose can decrease in vitro photosynthesis but improve field survival and growth of coconut (Cocos nucifera L.) in vitro plantlets. In Vitro Cellular and Developmental Biology - Plant, v.41, n.1, p.69-76, 2005. Online. Disponível na Internet http://www.ingentaconnect.com/ content/cabi/ivp.

GRATTAPAGLIA, D.; MACHADO, M.A. Micropropagação. In: TORRES, A.C. et al. Cultura de tecidos e transformação genética de plantas. Brasília: CBAB/Embrapa, 1998. p.183260 .

HARARIKA, B.N. Acclimatization of tissue-cultured plants. Current Science, Stamford, v.85, n.12, p.1704-1712, 2003.

HOFFMANN, A. et al. Efeito de substratos na aclimatização de plantas micropropagadas do porta-enxerto de macieira “marubakaido”. Ciência e Agrotecnologia, Lavras, v.25, n.2, p.462-467, 2001.

KADLECEK, P. et al. Importance of in vitro pretreatment for ex vitro acclimatization and growth. Plant Science, Limerick, v.161, p.695-701, 2001
KÄMPF, A.N. Produção comercial de mudas ornamentais. Guaíba: Agropecuária, 2000. 254p.

LEITE, G.B. et al. Efeitos de concentrações de sacarose no meio de cultura e da intensidade luminosa no enraizamento "in vitro" do porta-enxerto de pereira oh x f97. Ciência e Agrotecnologia, Lavras, v.24, n.2, p.353-357, 2000

MACIEL, A.L.R. et al. Aclimatação de plantas de violeta (Saintpaulia ionantha Wendl) obtidas in vitro: Efeitos do substrato. Ciência e Agrotecnologia, Lavras, v.24, n.1, p.9$12,2000$.

MONTANARI JÚNIOR, I. Aspectos do cultivo comercial do ginseng brasileiro (Pfaffia glomerata (Spreng) Pedersen). São Paulo: CPQBA-UNICAMP, 1999. 3p. (Boletim Agroecológico, 12).

MURASHIGE, T.; SKOOG, F. A revised medium for rapid growth and bioassays with tobacco tissue cultures. Physiologia Plantarum, Copenhagen, v.15, p.473-497, 1962.

NETO, A.A. et al. Avaliação de substratos alternativos e tipos de adubação para a produção de mudas de cafeeiro (Coffea arabica L.) em tubetes. Ciência e Agrotecnologia, Lavras, v.23, n.2, p.270-280, 1999

NICOLOSO, F.T. et al. Micropropagação do ginseng brasileiro. [Pfaffia glomerata (Spreng.) Pedersen]. Revista Brasileira de Plantas Medicinais, Botucatu, v.3, n.2, p.11-18, 2001

NICOLOSO, F.T. et al. Efeito de doses e fontes de carboidratos no crescimento e plantas de ginseng brasileiro [Pfaffia glomerata (Spreng.) Pedersen] cultivadas in vitro. Ciência e Agrotecnologia, Lavras, v.27, n.1, p.84-90, 2003.

SILVA, A.T. et al. Aclimatação de plantas provenientes da cultura in vitro. Pesquisa Agropecuária Brasileira, Brasília, v.30, n.1, p.49-53, 1995.

SKREBSKY, E.C. et al. Sacarose e período de cultivo in vitro na aclimatização ex vitro de ginseng brasileiro (Pfaffia glomerata (Spreng.) Pedersen). Ciência Rural, Santa Maria, v.34, n.5, p.1471-1477, 2004

TEDESCO, M.S. et al. Análise de solo, plantas e outros materiais. Porto Alegre: Universidade Federal de Porto Alegre, 1996. 174p. 